\title{
Safety and efficacy of combination chemotherapy regimens in older adults with pancreatic ductal adenocarcinoma: a systematic review
}

\author{
Patricia Saade-Lemus ${ }^{1,2}$, Leah Biller ${ }^{3}$, Andrea Bullock ${ }^{1 \wedge}$ \\ ${ }^{1}$ Department of Medicine, Division of Medical Oncology, Beth Israel Deaconess Medical Center, Harvard Medical School, Boston, MA, USA; \\ ${ }^{2}$ Department of Medicine, Beth Israel Lahey Health-Lahey Hospital and Medical Center, Tufts Medical School, Burlington, MA, USA; ${ }^{3}$ Department \\ of Medical Oncology, Dana Farber Cancer Institute, Harvard Medical School, Boston, MA, USA \\ Contributions: (I) Conception and design: P Saade-Lemus, A Bullock; (II) Administrative support: A Bullock; (III) Provision of study materials or \\ patients: P Saade-Lemus; (IV) Collection and assembly of data: P Saade-Lemus, L Biller; (V) Data analysis and interpretation: All authors; (VI) \\ Manuscript writing: All authors; (VII) Final approval of manuscript: All authors. \\ Correspondence to: Andrea Bullock, MD MPH. Division of Medical Oncology, Beth Israel Deaconess Medical Center, 330 Brookline Avenue, Boston, \\ MA 02215, USA. Email: abullock@bidmc.harvard.edu.
}

Background: Pancreatic ductal adenocarcinoma (PDA) is often diagnosed in older adults. However, most published studies investigating chemotherapy for PDA include a predominantly younger population, and the standard of care for the older adult population is not defined. It is our goal to review the literature available about the safety and efficacy of combination chemotherapy for locally advanced or metastatic PDA in older adults $\geq 65$ years.

Methods: We conducted a systematic review using Preferred Reporting Items for Systematic Reviews and Meta-Analyses (PRISMA) reporting checklist. We searched PubMed, EMBASE and MEDLINE databases to identify retrospective and prospective studies published until October 2018 that assessed the survival outcomes and adverse events in patients 65 years and older diagnosed with PDA and treated with combination chemotherapy.

Results: A total of 1,479 studies were screened. Twenty-four full-text studies were assessed for eligibility. Nineteen were excluded due to wrong study design $(n=4)$ or abstract only with no further publication $(n=15)$. A total of 5 full text studies met eligibility and were included in the present review. Combination chemotherapy is associated with similar survival to that reported in younger populations with advanced PDA. The most common toxicities across studies included: sensory neuropathy and neutropenia. Two studies each reported one death related to treatment-associated sepsis.

Discussion: Papers examined in this systematic review concluded that the use of combination chemotherapy regimens is safe and effective for older adults with minimal comorbidities and adequate performance status. Prospective data is needed to confirm these findings, provided that the most significant limitation of these studies was a small sample size.

Keywords: Pancreatic neoplasms; antineoplastic combined chemotherapy protocols; antineoplastic agents; aged; elderly

Submitted Feb 13, 2021. Accepted for publication Aug 05, 2021.

doi: 10.21037/jgo-21-87

View this article at: https://dx.doi.org/10.21037/jgo-21-87

$\wedge$ ORCID: 0000-0001-7143-0225. 


\section{Introduction}

Pancreatic ductal adenocarcinoma (PDA) is often diagnosed in older adults. The median age at diagnosis is 70 years, and the highest incidence is found among people aged $65-74$ years $(28.4 \%)$ followed by $75-84$ years $(24.7 \%)(1)$. However, most published studies investigating chemotherapy for PDA include a predominantly younger population, and some studies exclude older adults altogether. Single agent gemcitabine has been studied in patients $\geq 70$ years with unresectable PDA, and demonstrated safety and efficacy (mOS 10.3 months, $\mathrm{P}<0.05$ ) (2). Over the last decade, several phase III trials have shown that combination chemotherapy regimens are associated with improved survival compared to single agent regimens in patients with advanced PDA, although often at the expense of increased toxicity (3-5). How to apply these findings to older adults with PDA, however, is not well established in the scientific literature. In the MPACT study, older adults comprised $42 \%$ of the study population (4), while in the PRODIGE trial patients over age 76 were excluded (3). Our objective in this systematic review is to assess the safety and efficacy of combination chemotherapy regimens for locally advanced or metastatic PDA in older adults greater than 65 years of age.

We present the following article in accordance with the PRISMA reporting checklist (available at https://dx.doi. org/10.21037/jgo-21-87).

\section{Methods}

The PICOS (Population, Intervention, Comparison, Outcomes, and Study Design) inclusion and exclusion criteria used to perform the literature review are listed in Table 1.

A literature search of randomized controlled trials, retrospective cohort studies, prospective cohort studies and abstracts from national and international oncology meetings was conducted using the PubMed, EMBASE and MEDLINE databases, as well as ClinicalTrials. gov and ASCO.org. The search was performed using the following terms: Pancreatic Neoplasms [Mesh], Antineoplastic Combined Chemotherapy Protocols [Mesh], Antineoplastic Agents [Mesh], Aged [Mesh], Elderly [tiab] Others: non-resectable pancreatic adenocarcinoma, locally advanced pancreatic ductal adenocarcinoma, geriatric, age $* 65$, fluorouracil, leucovorin, folinic acid, oxaliplatin, gemcitabine, paclitaxel, capecitabine, folfox, folfirinox, capox.
The search was restricted to human studies published up to October 2018 in English. The study selection process was performed in the COVIDENCE software and is detailed in Figure 1.

Two investigators (P Saade-Lemus and L Biller) independently performed the literature search and selected eligible articles on the basis of prespecified inclusion criteria. For eligible studies, both authors extracted data and assessed study quality using the Newcastle-Ottawa Scale (6). Discrepancies were resolved by the senior author (A Bullock).

The following study characteristics were extracted: name of first author, title, journal, study design, date of publication, study duration (years), total number of participants, age range, sex, setting (country and number of institutions included), eligibility criteria, interventions (chemotherapy regimen, need for dose attenuation and prophylaxis, median follow-up), overall survival (OS), median overall survival (mOS), median progression-free survival (mPFS), response rate (RR) and grade 3/4 toxicities.

\section{Results}

\section{Study Selection}

The initial search identified 1,939 references imported for screening; 460 duplicates were removed, leaving 1,479 studies to screen of which 1,455 were not relevant to this review. Twenty-four full-text studies were assessed for eligibility. Nineteen were excluded due to wrong study design $(n=4)$ or abstract only with no further publication $(n=15)$. Studies categorized as wrong study design included: meta-analysis, insufficient results reported, or study population with age groups that did not meet inclusion criteria. A total of 5 full text studies met eligibility and were included in the present review.

\section{Study characteristics and results}

The compilation of results for the papers included in this article can be found in Table 2. Baldini et al. (7) describes a cohort of 42 subjects between the ages of 70-79 diagnosed with locally advanced or metastatic PDA at five institutions in France treated with FOLFIRINOX and followed for up to 86 months. Study population had the following characteristics: performance status $(0=15 \%, 1=24 \%$, $2=3 \%$ ), BMI (median $24 \mathrm{~kg} / \mathrm{m}^{2}$; range, $18-32 \mathrm{~kg} / \mathrm{m}^{2}$ ), concurrent medications $(\leq 3,24$ and $\geq 3,16)$. Also, Charlson comorbidity index at the time of diagnosis: median 10 ; 
Table 1 PICOS inclusion and exclusion criteria

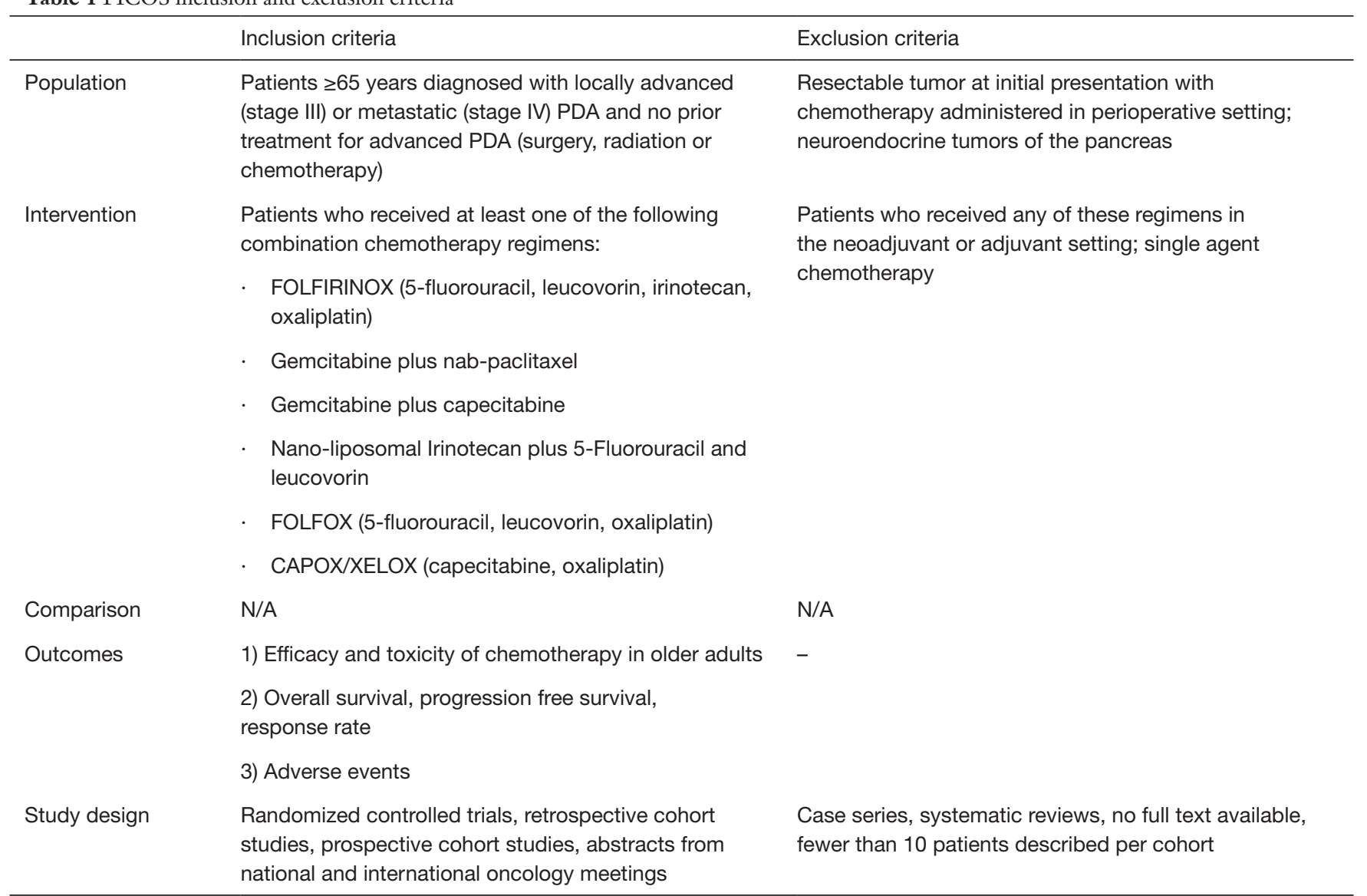

PICOS, Population, Intervention, Comparison, Outcomes, and Study design; N/A, not applicable.

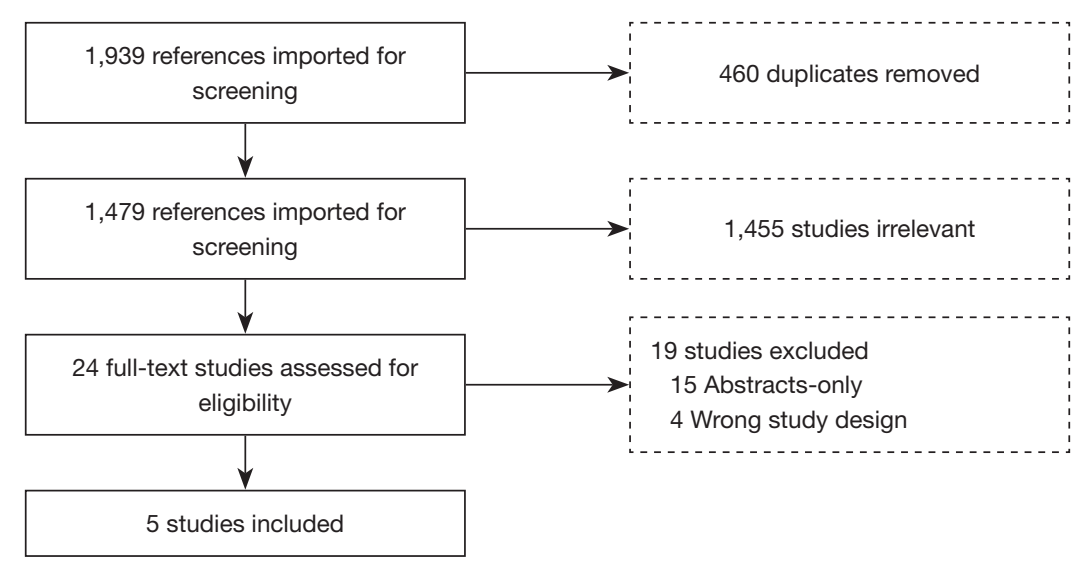

Figure 1 PRISMA flow chart. A total of 1,939 references were imported for screening, of which 460 duplicates were removed. 1,479 references were imported for screening, of which 1,455 were deemed irrelevant (these referenced include other types of GI tumors, other therapeutic regimens or study objective that were not related to this search). 24 full text studies were assessed for eligibility. Of these studies, 15 abstracts that did not result in a publication and 4 additional studies were excluded. This last 4 studies were defined as wrong study, by which we are referring to meta-analysis, insufficient results reported, or study population with age groups that did not meet inclusion criteria. Five studies were included in the final analysis. 
range, 9-12. Diabetes and hypertension were also included in the univariate analyses. Dose attenuation was necessary in $57 \%$ of cases, and primary prophylaxis with granulocytecolony stimulating factor (GCSF) was administered in $33 \%$. Median overall survival from time of diagnosis was 12.6 months (95\% CI: $1.7-150$ months) and from diagnosis of metastases 11.6 months (95\% CI: 1-74 months). Median OS for patients with locally advanced PDA was 49.5 months (95\% CI: 13.5-85.5 months). Primary dose reduction did not impact OS [11.7 months (6.9-16.4 months) compared to 16.6 months (0.37-32.8 months) without dose reduction, $\mathrm{P}=0.69]$. Twenty-nine percent experienced a grade $3 / 4$ toxicity with thrombocytopenia $(81 \%)$, neutropenia (71\%), asthenia (55\%) and sensory neuropathy $(23 \%)$ most often reported. One death was reported due to therapyrelated sepsis. Baldini and colleagues concluded that FOLFIRINOX is feasible and effective in selected, fit older adult patients.

There are two retrospective cohort studies conducted at a single institution in Germany reported by Berger et al. The first in 2014 (8) included 53 patients with histologically proven PDA, all $>70$ years and with median age 73 years (range, 70-89 years), treated with multiple regimens per attending oncologist. These included: gemcitabinebased regimens $(81.1 \%)$ and fluorouracil combinations ${ }^{1}$ : FOLFIRINOX (7.5\%), OFF (5.7\%), FOLFOX (3.8\%), and capecitabine $(1.9 \%) ; 30.2 \%$ required a dose reduction; no primary prophylaxis was reported. Median OS was 201 days (range, 17-1,480). Median OS for patients $\geq 75$ years was 145.5 days, and did not differ from those $<75$ years 218 days (95\% CI: 0.46-1.53 days, $\mathrm{P}=0.57$ ). Median OS for patients with ECOG PS 0 or 1 was 234.5 vs. 118 days for patients with ECOG $\geq 2$ (95\% CI: $1.38-S 4.52$ days, $\mathrm{P}=0.003$ ). Median PFS was 118 days (range, 17-597 days), with a significant difference between patients with ECOG 0 or 1 vs. ECOG $\geq 2$ of 234.5 days vs. 84 days, respectively ( $95 \%$ CI: $1.54-5.17$ days, $\mathrm{P}=0.008)$. $30.2 \%$ of patients experienced grade $3 / 4$ toxicities, most commonly hematotoxicity $20.7 \%$ and fatigue $5.7 \%$. Patients with an ECOG PS $\geq 2$ had a statistically significant shorter median duration of therapy (59 days) compared to those with ECOG PS $\leq 1$ (105 days; $\mathrm{P}<0.009)$. Berger and colleagues concluded that older patients did not have inferior outcomes compared to the reported trial populations that included predominantly younger patients.

In 2017, Berger et al. (9) reported on a retrospective cohort of 88 subjects with PDA treated with FOLFIRINOX. Two subgroups were identified: $<65$ years $(82 \%)$ and $\geq 65$ years $(17 \%)$. Dose attenuation was required in $56.8 \%$ of the total population and in $46.7 \%$ of the $\geq 65$ years subgroup. There was no difference in OS between the two subgroups. Among those $<65$ years, median OS was 11.2 months (95\% CI: 8.9-13.6 months), and among those $\geq 65$, median OS was 7.9 months (95\% CI: 5.8-10.0 months, $\mathrm{P}=0.83$ ). Median PFS for the entire cohort was 6.4 months (95\% CI: 5.7-7.2 months). Among those with ECOG PS 0, mPFS was 6.9 months (95\% CI: 6.2-7.6 months) compared to 5.4 months (95\% CI: 3.8-6.9 months) among those with ECOG PS 1, and 2.3 months (95\% CI: 1.0-3.6 months) among those with ECOG PS $2(\mathrm{P}=0.019)$. Toxicities in the $\geq 65$ years group included: fatigue (13.3\%), nausea/ vomiting $(13.3 \%)$, diarrhea (6.7\%), cholangitis $(6.7 \%)$, and thrombosis/PE (6.7\%). No therapy-related deaths were reported. The study concluded that age $\geq 65$ years was not associated with significantly different PFS or OS, nor were there significant differences in therapy interruptions, dosage modifications or grade $3 / 4$ toxicity.

Guion-Dusserre et al. (10) reported on a retrospective study of 34 subjects treated with FOLFIRINOX for locally advanced or metastatic PDA or colorectal cancer (mean age 74 years; range, $70-87$ years) at a single institution in France. $83.0 \%$ of the patients were $\geq 80$ years. Median OS among patients treated for PDA was 12.51 months (range, 8.85-17.2 months). The need for dose reduction occurred in $75 \%$ during cycle 1 . Toxicity data was presented for the combined colorectal and PDA populations and included: neutropenia $(32.7 \%)$, diarrhea $(5 \%)$, nausea $(9.6 \%)$, vomiting $(9.6 \%)$, asthenia (9.6\%), and anemia (9.6\%).

Bruera et al. (11) performed a Phase II prospective single arm trial of 29 patients at two institutions in Italy diagnosed with metastatic PDA that included a subgroup of 13 patients $(45 \%) \geq 65$ years. Patients received a modified regimen: FIr/ Fox. Median received dose intensities of the projected dose intensities, per patient, were: $70.4 \%$ 5-fluorouracil (5-FU), $70 \%$ irinotecan (CPT-11) and $72.5 \%$ oxaliplatin (OXP). Median OS for the entire cohort was 11 months (range, 0-33 months). Median PFS was 4 months (range, 0-21 months) for the entire cohort, and 4 months (range, 1-21 months) in the older adult subgroup. Median OS was significantly worse in patients with ECOG PS 2 when compared to ECOG PS $0-1$ [ 1 month (range, $1-3$ months) vs. 12 months (range, $0-33$ months), $\mathrm{P}=0.022]$; $\mathrm{PFS}$ was not significantly different $[1$ month (range, $1-3$ months) $v$ s. 4 months (range, $0-21$ months), $\mathrm{P}=0.078]$. Limiting toxicities, defined as grade 3-4 non-hematological toxicity, grade 4 hematologic toxicity, febrile neutropenia, or any toxicity 
determining $>2$ weeks treatment delay, were evaluated $(12,13)$. These were reported in $38.4 \%$ of the $>65$ years subgroup. Toxicities reported in the entire cohort included: diarrhea (17\%), neutropenia (17\%), and stomatitis/mucositis (6\%). The study concluded that intensive first-line triplet FIr/FOx is tolerable at modulated doses, and that PFS and mOS were not significantly worse in elderly compared to non-elderly patients $(\mathrm{P}=0.360$ and $\mathrm{P}=0.235$, respectively).

Additionally, fourteen abstracts were identified (Table 3) during the initial review. These were excluded from the main analysis because they did not result in a peer reviewed publication; most were presented in conferences with no further manuscripts. The efficacy and safety profile of combination regimens was comparable to that seen in the younger adult population. Dose attenuations were common, but AEs were manageable. One treatment-related death was reported on one of the abstracts (septic shock). Otherwise, no deaths were reported in the remaining abstracts.

\section{Discussion}

Older adults comprise a large proportion of patients with advanced PDA but are disproportionately excluded from clinical trials establishing safety and efficacy of combination chemotherapy. The PRODIGE trial establishing FOLFIRINOX as a standard of care regimen in advanced PDA included patients with median age 61 years and excluded patients $\geq 76$ years. The PRODIGE trial stated that age $>65$ years old was identified as an independent adverse prognostic factor for overall survival (HR 1.47, 95\% CI: 1.07-2.02, $\mathrm{P}=0.019$ ). In contrast, the PRODIGE group published another study by Conroy et al. (14) evaluating adjuvant FOLFIRINOX in patients with localized pancreatic adenocarcinoma, and showed that there was no statistically significant difference in overall survival between the $<70$ year group and those $\geq 70$ years (HE 1.16, 95\% CI: 0.89-1.52, $\mathrm{P}=0.28$ ). The MPACT trial included patients regardless of age, and those $\geq 65$ years were represented in proportion to that seen in the general population. Multivariable analysis showed that age was one of the statistically significant independent predictors of survival when comparing age $<65$ vs. $\geq 65$ (HR 0.81, 95\% CI: $0.69-0.96, \mathrm{P}=0.16$ ). How to optimally treat older adult patients greater than 65 years, however, is not well defined.

Combination chemotherapy in older adults has been studied in other gastrointestinal malignancies such as colorectal and gastric cancer. Goldberg et al. 2006 (15) performed a retrospective analysis of 3,742 patients diagnosed with colorectal cancer, including a subgroup of 614 patients $\geq 70$ years. Grade 3/4 toxicities were significantly higher in the older patients $(49 \%, \mathrm{P}=0.04)$ but the relative benefit as assessed by RR, $\mathrm{PFS}(\mathrm{P}=0.42)$, and OS $(\mathrm{P}=0.79)$ did not differ for FOLFOX4 (16) versus control in the older versus younger populations. Other studies using the FOLFOX regimen found similar results for older patients with colorectal cancer (17) and advanced gastric cancer (18). Sastre et al. (19) compared RR, TTP and OS outcomes of first-line oxaliplatin plus capecitabine in older patients with colorectal cancer $v s$. younger patients and concluded that older patients benefit from these combinations to the same degree as younger patients (mOS 16.8 months $>70$ years and 20.5 months $<70$ years, $\mathrm{P}=0.74$ ) without increased toxicity.

Papers examined in this systematic review concluded that the use of combination chemotherapy regimens is safe among older adults with few comorbidities and adequate performance status; and is associated with similar survival to what has been reported in younger populations with advanced PDA. The need for dose reductions was common throughout the studies evaluated in this review but was not associated with reduced survival. Dose reductions occurred more frequently in patients with longer treatment periods, suggesting cumulative toxicity with prolonged courses of chemotherapy. It is important to highlight that the lack of statistical significance in outcomes such as decrease in overall survival as reported by Baldini et al. (7) when a dose attenuation was required, might reflect a small sample size and warrants larger population studies.

Rather than age, performance status and comorbidities may be better predictors of treatment tolerance and benefit. Toward this end, Berger et al. recommend assessment of functional age by the Comprehensive Geriatric Assessment (CGA) (20) tool to assess eligibility for combination therapy (8).

The most common reported grade $3 / 4$ toxicities across studies included: sensory neuropathy and neutropenia. Neutropenia was addressed by primary prophylaxis with GCSF in one study. Two studies each reported one death related to treatment-associated sepsis $(7,8)$.

Guion-Dussere 2016 and Baldini 2016 evaluated the FOLFIRINOX regimen in older adults and concluded that its use is feasible in older adults, and primary dose reduction does not significantly impact OS. Berger et al. 2014 concluded that palliative chemotherapy should be considered independent from chronological age but adjusted for PS. While the sample sizes were small and 
Table 2 Data extraction

\begin{tabular}{|c|c|c|c|c|c|c|c|c|c|c|c|c|c|}
\hline \multirow[b]{2}{*}{ Source } & \multirow[b]{2}{*}{ Study design } & \multicolumn{3}{|c|}{ Participants } & \multicolumn{4}{|l|}{ Interventions } & \multicolumn{4}{|l|}{ Outcomes } & \multirow[b]{2}{*}{ Conclusions } \\
\hline & & $\begin{array}{l}\text { Total } \\
\text { number }\end{array}$ & $\begin{array}{l}\text { Median age } \\
\text { (range), years }\end{array}$ & Eligibility criteria & Chemotherapy regimen & $\begin{array}{l}\text { Dose } \\
\text { attenuation }\end{array}$ & $\begin{array}{l}\text { Prophylaxis } \\
\text { with GCSF }\end{array}$ & $\begin{array}{l}\text { Median } \\
\text { follow-up }\end{array}$ & mOS & mPFS & $\begin{array}{l}\text { Grade } \\
3 / 4 \text { toxicities }\end{array}$ & $\begin{array}{l}\text { Most frequent } \\
\text { toxicities (\%) }\end{array}$ & \\
\hline $\begin{array}{l}\text { Baldini } \\
\text { et al. (2017) } \\
\text { (7) }\end{array}$ & Retrospective & 42 & $73(70-79)$ & $\begin{array}{l}\text { Locally advanced or metastatic } \\
\text { pancreatic cancer, }>70 \text { years, } \\
\text { treated with } \geq \text { FOLFIRINOX, } \\
\text { PS (ECOG) }<2\end{array}$ & FOLFIRINOX & $57 \%$ & $\begin{array}{l}\text { Primary: } \\
(33 \%) \\
\text { Secondary: } \\
(26 \%)\end{array}$ & $\begin{array}{l}86 \text { months. } \\
\text { Median follow-up } \\
\text { since metastasis: } \\
40 \text { months }\end{array}$ & $\begin{array}{l}\text { Since diagnosis: } \\
12.6 \text { months. Since } \\
\text { metastasis: } \\
11.6 \text { months }\end{array}$ & N/A & $12(29 \%)$ & $\begin{array}{l}\text { Thrombocytopenia (81\%) } \\
\text { neutropenia }(71 \%) \\
\text { asthenia (55\%) } \\
\text { sensory /neuropathy (23\%) }\end{array}$ & $\begin{array}{l}\text { FOLFIRINOX is feasible and effective in selected, fit elderly } \\
\text { patients. Primary dose reduction does not impact survival } \\
\text { and might improve tolerance }\end{array}$ \\
\hline $\begin{array}{l}\text { Berger } \\
\text { et al. (2014) } \\
\text { (8) }\end{array}$ & Retrospective & 53 & $73(70-89)$ & $\begin{array}{l}\text { Histologic confirmed pancreatic } \\
\text { ductal adenocarcinoma, } \\
\text { advanced (inoperable), } \\
\text { age }>70 \text { at time of diagnosis of } \\
\text { advanced disease }\end{array}$ & $\begin{array}{l}\text { Gemcitabine }(41.5 \%) \text {, } \\
\text { Gem/Erlotinib }(37.7 \%) \text {, } \\
\text { FOLFIRINOX }(7.5 \%) \text {, } \\
\text { Gem/Cape (1.9\%), } \\
\text { OFF }(5.7 \%), \text { FOLFOX }(3.8 \%) \text {, } \\
\text { Cape (1.9\%) }\end{array}$ & $30.2 \%$ & N/A & $\begin{array}{l}297 \text { days } \\
\text { (17-1,480 days) }\end{array}$ & $\begin{array}{l}201 \text { days; } E C O G) \\
\text { or } 1: 234.5 \text { days; } \\
\text { ECOG >2: } 118 \text { days }\end{array}$ & $\begin{array}{l}118 \text { days; } \\
\text { ECOG } 0 \text { or } 1: \\
\text { s } 234.5 \text { days; } \\
\text { ECOG }>2: 84 \\
\text { days }\end{array}$ & $16(30.2 \%)$ & $\begin{array}{l}\text { Hematotoxicity (20.7\%), } \\
\text { fatigue (5.7\%) }\end{array}$ & $\begin{array}{l}\text { Older patients did not have inferior outcomes compared to } \\
\text { the reported trial populations. Palliative chemotherapy should } \\
\text { be considered independently from chronological age, with } \\
\text { consideration for PS }\end{array}$ \\
\hline $\begin{array}{l}\text { Berger } \\
\text { et al. (2017) } \\
\text { (9) }\end{array}$ & Retrospective & $\begin{array}{l}88 \\
(<65: 73) \\
(>65: 15)\end{array}$ & $56(32-78)$ & $\begin{array}{l}\text { Histologic proven pancreatic } \\
\text { ductal adenocarcinoma, } \\
\text { unresectable (metastatic or } \\
\text { locally advanced) }\end{array}$ & FOLFIRINOX ${ }^{\mathrm{a}}$ & $56.8 \%$ & N/A & $\begin{array}{l}150 \text { days } \\
\text { (14-787 days) }\end{array}$ & $\begin{array}{l}\text { 10.2 months; } \\
<65: 11.2 \text { months; } \\
>65: 7.9 \text { months } \\
(P=0.83)\end{array}$ & 6.4 months & $\begin{array}{l}46(52 \%) \\
<65: 56.2 \% \\
>65: 33.3 \%\end{array}$ & $\begin{array}{l}>65 \text { : fatigue }(13.3 \%) \\
\text { nausea /vomiting }(13.3 \%) \\
\text { diarrhea }(6.7 \%) \\
\text { cholangitis }(6.7 \%) \\
\text { thrombosis/PE (6.7\%) }\end{array}$ & $\begin{array}{l}\text { FOLFIRINOXa should not be withhold from patients with PDA } \\
\text { based solely on their chronological age but rather be based } \\
\text { on the patient's performance status and comorbidities. Age } \\
\geq 65 \text { years was not associated with significant difference in } \\
\text { PFS or OS }\end{array}$ \\
\hline $\begin{array}{l}\text { Guion- } \\
\text { Dusserre } \\
\text { et al. (2016) } \\
\text { (10) }\end{array}$ & Retrospective & $\begin{array}{l}52 \\
\text { (PDA: 34) }\end{array}$ & $74(70-87)$ & $\begin{array}{l}\text { Patients }>70 \text { years who } \\
\text { received FOLFIRINOX for } \\
\text { locally advanced or metastatic } \\
\text { pancreatic or colorectal cancer }\end{array}$ & FOLFIRINOX & $75 \%^{+}$ & N/A & N/A & $\begin{array}{l}\text { PDA: } 12.51 \text { months } \\
\text { Colorectal: } \\
43.38 \text { months }\end{array}$ & N/A & N/A & $\begin{array}{l}\text { Neutropenia }(32.7 \%) \\
\text { Diarrhea ( } 5 \% \text { ) } \\
\text { Nausea, vomiting, asthenia, } \\
\text { anemia }(9.6 \% \text { each), } \\
\text { NR for pancreatic cohort }\end{array}$ & $\begin{array}{l}\text { For people }>70 \text { years, FOLFIRINOXa was associated with } \\
\text { manageable toxicities and similar, even higher, median } \\
\text {, survival compared to younger people }\end{array}$ \\
\hline $\begin{array}{l}\text { Bruera } \\
\text { et al. (2018) } \\
\text { (11) }\end{array}$ & Phase II & $\begin{array}{l}29 \\
(\geq 65: 13)\end{array}$ & $62(48-76)$ & $\begin{array}{l}\text { Histologic/cytologic confirmed } \\
\text { diagnosis of measurable } \\
\text { metastatic PDA }\end{array}$ & $\mathrm{Flr} / \mathrm{Fox}^{\mathrm{d}}$ & N/A & N/A & 3 months & $\begin{array}{l}11 \text { months; elderly } \\
\text { group: } 5 \text { months }\end{array}$ & $\begin{array}{l}4 \text { months } \\
\text { Elderly group: } \\
\text { months }\end{array}$ & $\begin{array}{l}\text { Limiting } \\
\text { 4toxicity } \\
\text { syndrome in } \\
\geq 65: 38.4 \%\end{array}$ & $\begin{array}{l}\text { Diarrhea (17\%) } \\
\text { neutropenia (17\%) } \\
\text { stomatitis/mucositis (6\%), } \\
\text { NR for >65 }\end{array}$ & $\begin{array}{l}\text { Flr/FOx is tolerable at modulated doses, and is associated } \\
\text { with high activitylefficacy in metastatic PD; PFS and OS } \\
\text { were not significantly worse in elderly compared to } \\
\text { non-elderly patients }\end{array}$ \\
\hline
\end{tabular}

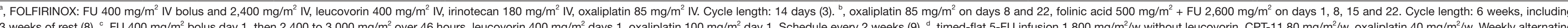

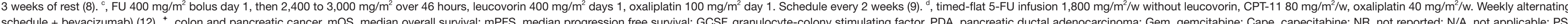
performance status; ECOG, Eastern Cooperative Oncology Group; FU, fluorouracil.

Table 3 Abstracts compilation

\begin{tabular}{|c|c|c|c|c|c|c|c|c|c|c|c|}
\hline \multirow[b]{2}{*}{ Source } & \multirow[b]{2}{*}{ Journal } & \multicolumn{2}{|l|}{ Participants } & \multicolumn{3}{|l|}{ Interventions } & \multicolumn{4}{|l|}{ Outcomes } & \multirow[b]{2}{*}{ Conclusions } \\
\hline & & Total number & $\begin{array}{l}\text { Median age, years } \\
\text { (range) }\end{array}$ & Chemotherapy regimen & $\begin{array}{l}\text { Dose } \\
\text { attenuation }\end{array}$ & $\begin{array}{l}\text { Median } \\
\text { follow-up }\end{array}$ & mOS & mPFS & $\begin{array}{l}\text { Grade } 3 / 4 \\
\text { toxicities }\end{array}$ & Most frequent toxicities (\%) & \\
\hline $\begin{array}{l}\text { Alessandretti } \\
\text { et al. (2015) }\end{array}$ & $\begin{array}{l}\text { Journal of Clinical } \\
\text { Oncology }\end{array}$ & 21 & $67(65-79)$ & FOLFIRINOX & NR & - & 11.8 months & 6.9 months & $7(33 \%)$ & $\begin{array}{l}\text { Anemia (62\%), nausea/vomiting (45\%), } \\
\text { elevated AST and/or ALT above upper } \\
\text { limit (38\%) }\end{array}$ & $\begin{array}{l}\text { Modified dose-attenuated FOLFIRINOX is a reasonable option for } \\
\text { elderly patients with advanced pancreatic adenocarcinoma. AEs were } \\
\text { manageable, no deaths due to toxicity. Median OS and PFS were similar } \\
\text { to phase III trials }\end{array}$ \\
\hline $\begin{array}{l}\text { Aoki et al. } \\
(2017)\end{array}$ & Annals of Oncology & $\begin{array}{l}\text { Total: } 28 \text {; elderly: 13; } \\
\text { non-elderly: } 15\end{array}$ & $\begin{array}{l}\text { Elderly: } 78 \text { (75-86); } \\
\text { non-elderly: } 69 \text { (54-73) }\end{array}$ & Gemcitabine + nab-paclitaxel & $\begin{array}{l}3(23 \%) \text { in the } \\
\text { elderly group }\end{array}$ & 1 year & $\begin{array}{l}1 \text { year survival: } \\
\text { elderly (50.8\%) } \\
\text { vs. non-elderly } \\
(57 \%)(P=0.75)\end{array}$ & NR & $\begin{array}{l}\text { Elderly: } 8(61 \%) \\
\text { non-elderly: } \\
7(47 \%)\end{array}$ & & $\begin{array}{l}\text { Efficacy and safety profile of Gemcitabine + nab-Paclitaxel in elderly } \\
\text { patients seemed to be comparable with non-elderly patients }\end{array}$ \\
\hline $\begin{array}{l}\text { Baldini et al. } \\
\text { (2015) }\end{array}$ & $\begin{array}{l}\text { European Journal of } \\
\text { Cancer }\end{array}$ & & $73(70-79)$ & FOLFIRINOX & $18(56 \%)$ & 18 months & 11.6 months & NR & $8(25 \%)$ & $\begin{array}{l}\text { Neuropathy }(75 \%) \text {, neutropenia }(34 \%), \\
1 \text { treatment related-death (septic shock) }\end{array}$ & $\begin{array}{l}\text { The } 11 \text { months median OS observed in elderly pts treated with } \\
\text { FOLFIRINOX was similar to OS previously reported in younger patients in } \\
\text { the ACCORD } 11 \text { trial. The dose of chemotherapy was reduced in half of } \\
\text { the patients }\end{array}$ \\
\hline
\end{tabular}

Table 3 (continued) 
Table 3 (continued)

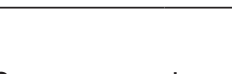

Participants Interventions

Chemotherapy regimen

Dose

Median
follow-up
NR

Braiteh et al. Journal

Outcomes

mPFS
NR
$(8$ months
N $P+G$ vs. 5.3
months G alone)

Grade $3 / 4$

Most

st frequent toxicities (\%)

(nab-P $P$ G) vs. gemcitabine
(G

nab-P+G vs. 5.3
months $G$ alone)

had fewer

discontinuation

(18\% vs. 26\%)

$\begin{array}{lll}\text { Giordano } & \text { European Journal of Total: } 145 \text {; subgroup } 65 \text { (37-86) } \\ \text { et al. (2015) } & \text { Cancer } & >75 \text { years old: } 25\end{array}$

et al. (2015) Cancer

Gemcitabine + nab-paclitaxel NR

NR

11.4 months 7.8 months $\quad N$

$\mathrm{NR}$

Giordano Journal of Clinical Total: 105; subgroup $64(37-77)$ Total: 105 ; subgroup
$>70$ years old: 37

Gemcitabine + nab-paclitaxel NR

NR

10 months 6.5 months Subgroup: non- NR hematological (27\%) hematolog

$(12 \%)$

Eisterer et al. Annals of Oncology Total: 219; subgroup 70 (44-89) $>70$ years old: 108

Gemcitabine + nab-paclitaxel $>70$ years old NR

$$
\begin{aligned}
& >70 \text { years old } \\
& \text { group }(\mathrm{N}=18)
\end{aligned}
$$

NR

5.1 months $\quad 66(46 \%)$ of the NR

in both total cohort

tal cohor

8.7 months NR

\begin{tabular}{|c|c|c|c|c|c|c|c|c|c|}
\hline $\begin{array}{l}\text { Gomes et al. } \\
(2016)\end{array}$ & $\begin{array}{l}\text { Journal of Clinical } \\
\text { Oncology }\end{array}$ & 50 & $71(65-83)$ & FOLFIRINOX & Yes & NR & 28.3 months & 18.7 months & NR \\
\hline $\begin{array}{l}\text { Kaino et al. } \\
\text { (2017) }\end{array}$ & $\begin{array}{l}\text { Journal of } \\
\text { Gastroenterology } \\
\text { and Hepatology }\end{array}$ & $\begin{array}{l}\text { Total: } 86 ; \text { subgroup } \\
>75 \text { years old: } 27\end{array}$ & NR & FOLFIRINOX & NR & NR & 332 days & NR & $\begin{array}{l}\text { Subgroup } \\
>75 \text { years old: } \\
18.2 \%\end{array}$ \\
\hline Machalaki & Annals of Oncology & 28 & $72(70-78)$ & Gemcitabine + nab-paclitaxel & NR & NR & 12.8 months & 7.4 months & $27(100 \%)$ \\
\hline
\end{tabular}

Machalaki Annals of Oncology 28

$72(70-78)$

Gemcitabine + nab-paclitaxel NR

12.8 months $\quad 7.4$ months $\quad 27(100 \%)$

Gemcitabine + capecitabine NR NR

9.4 months $\quad$ NR $\quad 12(33 \%)$

Vasiliki et al. Annals of Oncology 38

$>75$

(2017)

$73(70-79)$

Ventriglia Annals of Oncology 46

Gemcitabine + nab-paclitaxel NR

NR

12 months

7 months

$31(67 \%)$

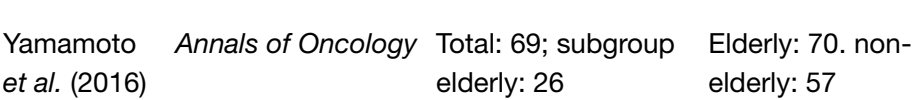

FOLFIRINOX

Ishii et al. Pancreatology Total: 22; group A NR

(2016) (>65 years old): 10

vs. $42 \%$ Group

NR

Conclusions

Similar to the benefit demonstrated in MPACT trial comparing nab $-P+G$ with $G$, patients receiving nab- $P+G$ experienced significantly longer
median mOS vs. G. More supportive care may have been used in the nab- $P+G$ group due to longer treatment duration

Reinforcement of the role of Nab- $P+G$ as a standard of care in advanced PDA first line setting, showing activity, efficacy and safety also in elderly, ECOG PS 2 and biliary stent carriers patients

Patients aged $\geq 70$ may benefit of first-line Nab-P $+G$ combination, as well as younger ones, both in terms of response and survival experiencing a tolerable, but significantly different toxicity profile

Presented the effectiveness and tolerability of nab- $P+G$ in the clinical routine treatment of metastatic pancreatic cancer patients including a large cohort of elderly patients $>70$ years

Diarrhea (14.3\%), nausea (2.8\%), fatigue Dose-attenuated FOLFIRINOX is a well-tolerated regimen in the elderly (11.4\%), neuropathy (5.7\%) population, and should also be considered a reasonable first-line therapy for those patients with good PS

Chemotherapy could be safe and effective for patients older than

75 years who have unresectable PDA

Neutropenia (11\%), peripheral neuropathy $(3.5 \%)$ thrombocytopent $(7 \%)$, diarrhea (11\%), nausea and

Patients aged 70+ may benefit of first-line gemcitabine plus nabPaclitaxel combination, as well as younger ones, both in terms nabresponse and survival experiencing a tolerable, toxicity profile vomiting $(3.5 \%)$, fatigue $(11 \%)$

Hand-foot syndrome (9\%), diarrhea Tolerance and efficacy of gemcitabine in combination with capecitabine (7\%), thrombocytopenia (3\%), and febrile neutropenia (4\%) younger patients
yorly patients in good condition, with similar results Neutropenia (10\%), peripheral

Combination of gemcitabine plus nab-paclitaxel is effective and safe in
an unselected population of elderly patients showing no differences in (4\%), diarrhea (6.5\%) outcome between older patients and younger patients treated with this

Elderly group: neutropenia (54\%), febrile FOLFIRINOX treatment is tolerable and active for the elderly patients with advanced PDA, although frequency of severe neutropenia is higher in the cotFinOX therapy in the elderly patients wito FOLFRINOX therapy in the elderly patients with unresectable pancreat cancer may be safe and effective according to dose reductions of

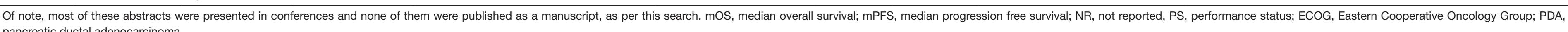


results inconclusive, Berger and colleagues (9) concluded that FOLFIRINOX is safe in fit older adults and should not be withheld from patients based solely on chronologic age.

\section{Limitations}

The majority of studies included in this review were retrospective. In addition, the small sample sizes and limited number of institutions at which they were performed limit power and generalizability. Importantly, the definition for older adult age varied across studies, from 65 to 80 years. It is not possible to draw firm conclusions about any one regimen from these results, which focus on combination chemotherapy altogether.

\section{Conclusions}

In conclusion, the available literature presented in this systematic review suggests that the use of combination chemotherapy regimens is safe and effective for older adults with minimal comorbidities and adequate performance status. The validity of these results is limited by their small sample-size populations but should prompt physicians to consider these factors, rather than age alone, in their decision making when treating older adults with PCA. Prospective data is needed to confirm these findings and determine the optimal regimen in this population.

\section{Acknowledgments}

We appreciate the support provided by Paul Bain, Librarian, Countway Library, Harvard Medical School, in preparation of this manuscript.

Funding: None.

\section{Footnote}

Reporting Checklist: The authors have completed the PRISMA reporting checklist. Available at https://dx.doi. org/10.21037/jgo-21-87

Peer Review File: Available at https://dx.doi.org/10.21037/ jgo-21-87

Conflicts of Interest: All authors have completed the ICMJE uniform disclosure form (available at https://dx.doi. org/10.21037/jgo-21-87). AB participated on academic advisory boards for Geistlich Pharma and Exelixis. The other authors have no conflicts of interest to declare.

Ethical Statement: The authors are accountable for all aspects of the work in ensuring that questions related to the accuracy or integrity of any part of the work are appropriately investigated and resolved.

Open Access Statement: This is an Open Access article distributed in accordance with the Creative Commons Attribution-NonCommercial-NoDerivs 4.0 International License (CC BY-NC-ND 4.0), which permits the noncommercial replication and distribution of the article with the strict proviso that no changes or edits are made and the original work is properly cited (including links to both the formal publication through the relevant DOI and the license). See: https://creativecommons.org/licenses/by-nc-nd/4.0/.

\section{References}

1. Howlader N, Noone AM, Krapcho M, et al. SEER Cancer Statistics Review 1975-2014 Bethesda, MD, 2017. Available online: https://seer.cancer.gov/csr/1975_2014/

2. Yamagishi $Y$, Higuchi $H$, Izumiya $M$, et al. Gemcitabine as first-line chemotherapy in elderly patients with unresectable pancreatic carcinoma. J Gastroenterol 2010;45:1146-54.

3. Conroy T, Desseigne F, Ychou M, et al. FOLFIRINOX versus gemcitabine for metastatic pancreatic cancer. $\mathrm{N}$ Engl J Med 2011;364:1817-25.

4. Von Hoff DD, Ervin T, Arena FP, et al. Increased survival in pancreatic cancer with nab-paclitaxel plus gemcitabine. N Engl J Med 2013;369:1691-703.

5. Wang-Gillam A, Li CP, Bodoky G, et al. Nanoliposomal irinotecan with fluorouracil and folinic acid in metastatic pancreatic cancer after previous gemcitabine-based therapy (NAPOLI-1): a global, randomised, open-label, phase 3 trial. Lancet 2016;387:545-57.

6. Clinical Epidemiology Program. Available online: https:// www.ohri.ca/programs/clinical_epidemiology/

7. Baldini C, Escande A, Bouché O, et al. Safety and efficacy of FOLFIRINOX in elderly patients with metastatic or locally advanced pancreatic adenocarcinoma: A retrospective analysis. Pancreatology 2017;17:146-9.

8. Berger AK, Abel U, Komander C, et al. Chemotherapy for advanced pancreatic adenocarcinoma in elderly patients ( $\geq 70$ years of age): a retrospective cohort study at the National Center for Tumor Diseases Heidelberg. Pancreatology 2014;14:211-5. 
9. Berger AK, Haag GM, Ehmann M, et al. Palliative chemotherapy for pancreatic adenocarcinoma: a retrospective cohort analysis of efficacy and toxicity of the FOLFIRINOX regimen focusing on the older patient. BMC Gastroenterol 2017;17:143.

10. Guion-Dusserre JF, Bertaut A, Ghiringhelli F, et al. Folfirinox in elderly patients with pancreatic or colorectal cancer-tolerance and efficacy. World J Gastroenterol 2016;22:9378-86.

11. Bruera G, Massacese S, Candria S, et al. Real life triplet $\mathrm{FIr} / \mathrm{FOx}$ chemotherapy in first-line metastatic pancreatic ductal adenocarcinoma patients: recommended schedule for expected activity and safety and phase II study. Oncotarget 2018;9:31861-76.

12. Bruera G, Cannita K, Giordano AV, et al. Effectiveness and safety of intensive triplet chemotherapy plus bevacizumab, FIr-B/FOx, in young-elderly metastatic colorectal cancer patients. Biomed Res Int 2013;2013:143273.

13. Bruera G, Russo A, Galvano A, et al. Clinical parameters to guide decision-making in elderly metastatic colorectal CANCER patients treated with intensive cytotoxic and anti-angiogenic therapy. Oncotarget 2017;8:37875-83.

14. Conroy T, Hammel P, Hebbar M, et al. FOLFIRINOX or Gemcitabine as Adjuvant Therapy for Pancreatic Cancer. N Engl J Med 2018;379:2395-406.

15. Goldberg RM, Tabah-Fisch I, Bleiberg H, et al. Pooled analysis of safety and efficacy of oxaliplatin

Cite this article as: Saade-Lemus P, Biller L, Bullock A. Safety and efficacy of combination chemotherapy regimens in older adults with pancreatic ductal adenocarcinoma: a systematic review. J Gastrointest Oncol 2021;12(6):2591-2599. doi: 10.21037/ jgo-21-87 plus fluorouracil/leucovorin administered bimonthly in elderly patients with colorectal cancer. J Clin Oncol 2006;24:4085-91.

16. Goldberg RM, Sargent DJ, Morton RF, et al. A randomized controlled trial of fluorouracil plus leucovorin, irinotecan, and oxaliplatin combinations in patients with previously untreated metastatic colorectal cancer. J Clin Oncol 2004;22:23-30.

17. Figer A, Perez-Staub N, Carola E, et al. FOLFOX in patients aged between 76 and 80 years with metastatic colorectal cancer: an exploratory cohort of the OPTIMOX1 study. Cancer 2007;110:2666-71.

18. Liu ZF, Guo QS, Zhang XQ, et al. Biweekly oxaliplatin in combination with continuous infusional 5 -fluorouracil and leucovorin (modified FOLFOX-4 regimen) as first-line chemotherapy for elderly patients with advanced gastric cancer. Am J Clin Oncol 2008;31:259-63.

19. Sastre J, Aranda E, Massutí B, et al. Elderly patients with advanced colorectal cancer derive similar benefit without excessive toxicity after first-line chemotherapy with oxaliplatin-based combinations: comparative outcomes from the 03-TTD-01 phase III study. Crit Rev Oncol Hematol 2009;70:134-44.

20. Maas HA, Janssen-Heijnen ML, Olde Rikkert MG, et al. Comprehensive geriatric assessment and its clinical impact in oncology. Eur J Cancer 2007;43:2161-9. 